\title{
FUNDAMENTOS ESTRUCTURALES DE LA EXPERIENCIA CORPORAL
}

\section{STRUCTURAL ABC OF THE CORPOREAL EXPERIENCE}

Miguel Ángel Molano ${ }^{1}$

Resumen

En la búsqueda de elementos estructurales que ayuden a comprender el sentido y los fundamentos de la experiencia corporal, se presentan, inicialmente, diversas manifestaciones del reduccionismo del cual la experiencia corporal es objeto, en el marco de la cultura denominada "occidental". Llegaremos luego, en este andar, a un cruce de caminos entre cultura, natura y subjetividad alrededor del cuerpo, en cuya complejidad nos detendremos a revisar las dimensiones y elementos estructurales desde las cuales se configura la experiencia corporal. En esta ruta, aún por explorar profundamente, identificaremos diversas relaciones desde las cuales la Educación Física retomaría elementos para enriquecer y potenciar la experiencia corporal.

Palabras clave: Experiencia corporal, cuerpo, extensión, introyección, proyección.

Abstract

Initially a search of a structural $\mathrm{ABC}$ helps to understand the meaning and basis of the corporeal experience. Then we submit several reductionism hints from which the body experience is a target in a so-called "Western" culture. Later we will speak about a crossing between nature, culture and subjectivity around the body whose complexity will lead us to check dimensions and structural elements to make up the corporeal experience. Walking this even unexplored path, we will recognize different relations from which the PE would resume rudiments to enrich and enhance the body experience.

Keywords: Corporal experience, body, extension, introjection, projection.

Fecha de recepción: 16 de mayo de 2012

Fecha de aprobación: 19 de septiembre de 2012

1 Especialista en Docencia Universitaria y licenciado en Educación Física. Docente catedrático del proyecto curricular en Educación Física de la Facultad de Educación Física, Universidad Pedagógica Nacional. Coordinador del grupo de investigación Complexus: Didáctica de la Educación Física y Desarrollo Humano. Correo electrónico: mimolab2000@hotmail.com 


\section{Preámbulo}

Retomando el principio de incertidumbre planteado por Werner Heisemberg (www.wikipedia.org), lo imagino observando el electrón y sumido en la disyuntiva de interpretarlo como un corpúsculo que se ubica en un espacio determinado, pero sin poder anticipar su trayectoria, o verlo como una onda, que fluye en la sucesión del tiempo pero sin poder ser ubicada en el espacio. Esta incertidumbre le lleva a ir más allá de una perspectiva centrada en el objeto y tomar posición, obligándolo a involucrarse como sujeto, en tanto necesita autorreferenciarse y así poder, desde su perspectiva, interpretar lo que observa ${ }^{1}$, optando por una de las dos perspectivas (¿es cuerpo?, ¿es onda?), identificando el paradigma desde el que referencia su postura (¿o impostura?) y así reconocerse en su subjetividad. ¿Un nuevo dualismo? ¿Una nueva dicotomía? No. Se trata de reconocer que la realidad es más densa, más compleja de lo que la razón infiere, y es necesario ampliar el marco de referencia.

El caso de Heisemberg me deja pensando que la Educación Física está en el momento de buscar su propio principio de incertidumbre. Así pues, ubicado en el patio con mis estudiantes, me observo observando y me encuentro con la aparente paradoja que nos plantea Luis Not:

Un tratamiento racional ordenado hacia un conocimiento objetivo supone la distinción expresa entre el sujeto que conoce y el objeto a conocer. Esto no ocurre cuando el sujeto forma cuerpo con la situación estudiada. (...) Nos encontramos aquí con la dificultad característica de la experiencia existencial que es la imposibilidad de estar al mismo tiempo en el interior de la situación para vivirla y en el exterior para analizarla objetivamente. (Not, 1994, p.186)

Esta situación contradictoria la puedo ver en el patio de clase, donde en la cotidianidad veo cuerpos predeterminados por sus imperativos biológicos, en permanente tensión y ajuste con los imperativos sociales. Pero hay algo allí de incierto: no sé si ver o centrarme en los cuerpos actuantes o en la volatilidad de lo que en un instante expresan. Descubro entonces, en esta incertidumbre, otro cuerpo: el cuerpo subjetivo, fuente de la experiencia corporal. En la búsqueda de elementos que me ayuden a aprehender ese cuerpo volátil, o quizá onda incierta -¿cómo verle?-, inicio un

1 La percepción de "...la casa, sin una perspectiva desde la cual se puedan derivar otras, es una casa vista desde ninguna parte (...) una representación sin sentido y sin significado". (Merleau-Ponty, 1975, p. 73). camino en contravía de los reduccionismos que del cuerpo genera la cultura del consumo.

Así pues, me ignoro partícula, me monto en mi moto, extiendo mi esquema corporal y me convierto en una... Honda...

\section{La reducción de la experiencia corporal}

Ser lo que no es, y no ser lo que es:
esa es la naturaleza del hombre.
Nicola Abagnano (1997, p. 23).

Siguiendo la pista al concepto de experiencia, nos hallamos desandando el camino por el cual en nuestra cultura fragmentada, utilitaria y consumista se objetiva al cuerpo como un instrumento, o deviene en imagen al modelarlo desde unos usos sociales en los cuales la experiencia corporal se reduce a actividad física ${ }^{2}$, perfilándose desde este reduccionismo un sutil mecanismo de expropiación del cuerpo.

Desandando este camino, en esta búsqueda nos encontramos con que hablar de cuerpo, desde alguna perspectiva histórica, es referirse a "ese oscuro objeto" del deseo como una cosa, receptáculo, transportador del alma, los pecados, la culpa, la patria, la especie... en fin, el cuerpo es comprendido como un corpúsculo ubicuo en el espacio-tiempo. Desde las ciencias exactas, el cuerpo es reducido a un análisis mecánico del movimiento, que redunda en unas técnicas de movimiento que poco o nada dicen de la experiencia vivida, de las necesidades, deseos, fantasmas desde los que nace ese movimiento. Visto como un corpúsculo ubicado (y determinado) en un tiempo, unas circunstancias, un "aséptico" espacio vital, así es trabajado en la educación física y las ciencias que la auxilian ${ }^{3}$, a partir de unas actividades que desde una perspectiva biologista, se reducen a propiciar el desarrollo de unas funciones corporales (orgánicas-metabólicas, óseo-musculares

2 "Occidente retoma las experiencias corporales de otras culturas y las reduce a sus técnicas" (Notas de clase con el profesor Hernán Felipe Prieto, 1996). No se trata aquí de rechazar la necesidad de desarrollar una buena condición física, sino de la reducción de la experiencia del ejercicio a su carácter fisiológico, desconociendo sus condiciones volitivas, sus posibilidades experienciales.

3 Su biomecánica (cuerpo sujeto a las fuerzas físicas). La fisiología (cuerpo sujeto de sus funciones y disfunciones), músculos (resortes), huesos (palancas). Biología y nutrición: alimento, calorías, cuerpo-masa predeterminada por el entorno (inercias, fuerzas centrípetas y centrífugas...). 
y perceptivo-motrices). Vemos aquí un desplazamiento claro de la experiencia vivida, entendida como acto significado por sí mismo y ejecutado para sí mismo, hacia el desarrollo de una actividad, entendida como acto realizado para el logro de un propósito asignado a la actividad, que redunda en la objetivación del cuerpo.

Ilustrando este desplazamiento reduccionista de la experiencia a la actividad, tomemos el correr, un acto que puede ejecutarse en una campiña o en una banda rodante. Tomado como actividad, pueden tener el mismo carácter, pero no así como experiencia, donde difiere su sentido.

En la banda rodante, el acto de trotar no se hace por sí mismo, sino que se le superpone una simbología que le expropia su carácter de experiencia. Reducido a una operación humana conducente a dar salud, en tanto desarrollo funcional de los sistemas metabólico y óseo-muscular, empobrece los sentidos, los adormece en la seguridad y en los actos propios de la routine (una rueda que gira en el vacío). En la medida de cuántos minutos, cuántos kilos, cuántas calorías, expropia de significado propio al acto de correr, quedando condicionado a un hacer para, un fin ajeno al acto mismo.

En contraste con lo anterior, en el acto de trotar en la campiña, para el caso que quiero ilustrar, es factible ir más allá de su carácter funcional, enriqueciendo el acto mismo, al impregnarse nuestros sentidos de lo diverso del paisaje, de lo incierto del camino, el descubrimiento de los ritos y capacidades propios, al no estar supeditado el cuerpo a la máquina; hasta el olvido de sí, el abandono... a no ser el deportista que trota y no puede parar, a quien se le podría preguntar: Deportista: ¿quién te dijo que no puedes parar? ¿No te seduce el paisaje? ¿Qué tanto importan el tiempo y la distancia? Medidos, demarcados están ya. Las prácticas corporales, en este caso trotar, son mediaciones de nuestro ser con el mundo. Pero se ilustra en los dos casos anteriores, como cuando los medios devienen en fines se trastoca el sentido de las prácticas y redundan en empobrecimiento de la experiencia corporal.

Otro reduccionismo generalmente aceptado se evidencia cuando, fundamentada en un falso dualismo cuerpomente, la actividad del cuerpo es instrumentalizada por la Educación Física para, a través de ella, introyectar nociones, conceptos e, implícitamente, relaciones de poder, normas, modelos desde los cuales se forma al cuerpo en un tiempo y un espacio restrictivos, poniendo ese cuerpo al servicio de algunos aprendizajes que apuntan al logro de objetivos ajenos al propio desarrollo del cuerpo, que al descorporalizar el cuerpo lo convierte en una máquina perfecta al servicio de la inteligencia... Un cuerpo mecánico expresión de la razón (Denis, 1986, p. 62) ¿No tiene, por sí misma, la experiencia de ser cuerpo su propio estatuto cognitivo?

Vamos viendo cómo opera esa fuerte tendencia a objetivar la experiencia, reduciéndola a sus caracteres exteriores y dejando de lado la reflexión sobre cómo el movimiento circunscrito a la actividad predeterminada, repercute al interior del cuerpo. Es así como, desde una perspectiva sociológica (con fundamento en el psicoanálisis), se ha visto que la excesiva normatividad, el fuerte predominio del "principio de realidad" ha implicado un exceso de represión sobre el principio del placer, generando en el individuo y en la sociedad en su conjunto una híper-represión que, en últimas, se da sobre los cuerpos, redunda en una sublimación del consumo. Cuerpos que consumen referentes simbólicos desde el cine (el héroe), los conciertos masivos (el ídolo de moda) y los personajes estereotipos de la televisión, desde los cuales:

El cuerpo es modelado para emitir las imágenes reificadas de una identidad imposible pero intensamente deseada por la gran masa, al punto de generar industrias de transformación del cuerpo (tintes, cirugía plástica, modas y accesorios) que permiten en mayor o menor medida aproximarse a un modelo ideal de cuerpo. Con los dispositivos creadores de estas fantasías, el cuerpo, en tanto imagen, se desprende e independiza, en cierta medida, del cuerpo sensorial, del cuerpo que percibe. (Pinzón, 1997, p. 210)

Figura 1: El mecanismo publicitario

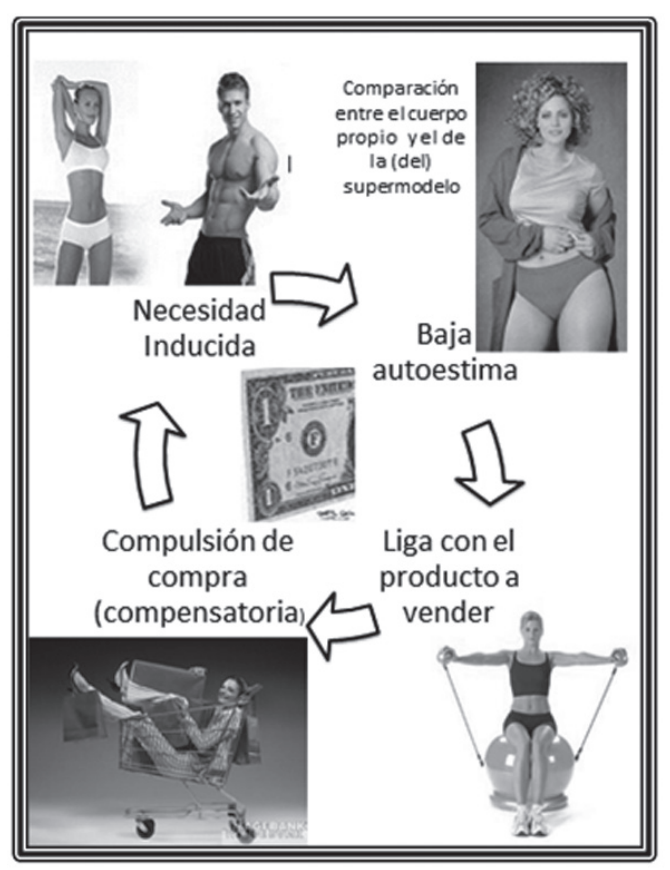


Hállese un deseo corriente, algún difundido temor o ansiedad inconsciente. Estúdiense los posibles nexos de este sentir inconsciente, con el producto a vender. Constrúyase un puente de símbolos verbales o pictóricos por los cuales el cliente pueda pasar del hecho a un sueño compensatorio y del sueño a la ilusión de nuestro producto. (Huxley, 1998, p. 59)

Este hecho se puede observar en los procesos del mercado y la publicidad, en los cuales se da un proceso de sublimación de la imagen del cuerpo mediante la transferencia de los atributos "del objeto" (cuerpo) a la imagen (modelo social, héroe, ídolo). Pero esta transferencia está mediada, como lo vimos arriba, por la tensión entre la búsqueda de esta identidad imposible y la negación del intenso deseo de acceder a ella; tensión cuyos costos personales y sociales son devastadores ${ }^{4}$. Dado que a un problema real, tangible, se le da una solución por los medios publicitarios y de mercado, mediante un proceso de compensación a un nivel simbólico, aparentemente queda resuelto el problema, pero la tensión queda reprimida en los niveles inconscientes. Así pues, la necesidad creada por el consumo es suplida de manera simbólica, pero generando una ruptura con las percepciones que el sujeto tiene de sí. Identidad imposible que termina en la "desterritorialización del cuerpo" (Deleuze, 1974). Un cuerpo sin arraigo en un territorio, que ocupa un espacio vacío de sentido. Intenso deseo que termina en la llenura insatisfecha del consumo. En el tedio (un tiempo vacío por llenar).

Así pues, cuerpos en serie, aptos para el consumo, reprimida la diversión (divergente versión) del cuerpo, nos abandonamos al dispositivo publicitario que, por un lado, anula los filtros perceptivos que nutren la conciencia y la razón (la consigna publicitaria, eslogan que anula la mente y no permite pensar), resaltando la sensibilidad del cuerpo como fuente de necesidades a satisfacer (Chomsky, 2002), haciéndolo instrumento que consume, en tanto que, por otro lado, hace énfasis en la fuerza de verdad de la imagen publicitaria que presen-

4 Carlos Pinzón ilustra algunos casos particulares: Elvis Presley, Marilyn Monroe, Kid Pambelé. Otro ejemplo puede ser la manipulación de la identidad como necesidad de arraigo a un grupo social y a un territorio, cuando se compensa con el ser hincha de un equipo de fútbol, a sabiendas de que esta necesidad de arraigo se hace dependiente de los atributos que a un nivel simbólico tiene el valor de ser hincha (competencia, éxito, derrota...). La autoestima propia, la autoestima de todo un pueblo ligada al rendimiento de un equipo: peligroso. Una bomba explosiva inestable. Desastroso. ta, anulando las necesidades efectivas del cuerpo: "La imagen es nada, tu sed es todo. Consume...". Un proceso publicitario que "anula la mente", que "anula al cuerpo", ¿qué deja? Un cuerpo virtual silenciado en lo que vive, anestesiado de sí, reducido a los hipertrofiados sentidos de distancia que construye una sociedad que todo lo abarca con la mirada y la palabra, pero no toca, no olfatea ni degusta. Y más aún, no construye autorreferencias. Se reitera: ¿qué queda? Un cuerpo virtual.

\section{La onda del cometa, o el camino de la experiencia corporal}

"El bailarín es sujeto y objeto a la vez, de su arte. Es, al mismo tiempo, y en el mismo espacio, escultor y escultura, navegante y nave, domador y fiera". Álvaro Restrepo.

Desandando el camino desde la no experiencia hacia aquello que la constituye, llegamos a una encrucijada: allí donde se cruzan los caminos en los que natura y cultura conforman el cuerpo. Y es allí donde observamos la permanente tensión, ruptura y reorganización entre el cuerpo y sus determinantes biológicas, psicológicas y culturales, donde se construye la experiencia corporal.

Para fundamentar este planteamiento, de manera alegórica podríamos decir que poseemos tres cuerpos. El cuerpo biológico, que responde a los imperativos de supervivencia, desarrollo y maduración de las estructuras y sistemas anatómico-funcionales que configuran un biotipo: "El mono erguido" 5 . El cuerpo social, en el cual la cultura introyecta unos "usos sociales del cuerpo" y unas "técnicas del cuerpo" que son interiorizadas mediante códigos lingüísticos, sistemas normativos de regulación y en procesos y procedimientos técnicos en el manejo de los artefactos propios de una cultura.

En la tensión, conflicto y empalme del cuerpo biológico, que se desarrolla y madura, con el cuerpo que es construido y modelado por la cultura, emerge, se estructura un tercero, el cuerpo subjetivo, que es vivido, sentido, percibido y que, a su vez, vive, siente y percibe su entorno. Cuerpo fuente de pulsiones, deseos, sueños. Cuerpo que significa y es significado. Cuerpo que es, a la vez, sujeto y objeto de su experiencia de ser.

5 La bipedestación y la especialización de la mano que determinan y posibilitan nuestras formas características de locomoción y manipulación, como bien nos lo expresó Engels. 
Es en este plano del cuerpo subjetivo donde la experiencia corporal expande los límites que le determinan los imperativos del cuerpo biológico y del cuerpo social. En la encrucijada de los cuerpos biológico y social, el cuerpo subjetivo va más allá de su destino y sus circunstancias -destino, azar, opciones, circunstancias. ¿Qué puede el cuerpo en ese juego?-; extiende sus límites, se explora explorando y, más allá de la actividad escueta, resignifica su experiencia en un entramado simbólico. Este carácter subjetivo es una síntesis de las tensiones natura-cultura, que no pueden verse de manera dicotómica.

Me explico: vivimos en permanente contacto con el mundo. Una acción sobre el mundo está inmersa en un conjunto de retroacciones que reorientan mi acción: conduzco un balón e, inmediatamente, por mis sentidos, recibo el dato de su peso, su resistencia al desplazamiento, y momento a momento revierte en regulaciones de mi propia acción. Claro, el objeto en sí no tiene intención de retroalimentarme, pero en la clase de educación física, el objeto es una mediación cultural y está cargado de intenciones: un balón tiene una marca, unas características que posibilitan unas acciones y no otras, y responde a una intención pedagógica por parte del maestro. No es un objeto pasivo. Está cargado de intenciones y posibilidades de acción, de interacción y de significación ${ }^{6}$.

Retomando el comentario inicial de este ensayo sobre el principio de incertidumbre, hacer una mirada distinta sobre "el objeto" implica revisar los conceptos propios ${ }^{7}$ : cuerpo- movimiento, cuerpo 602 sensibilidad, tiempo 0002 espacio, lenguaje 6000 conocimiento, ameritan una interpretación distinta desde la perspectiva de la experiencia corporal. Así pues, ¿desde cuales categorías, ejes, núcleos podríamos entrar a estudiar este difuso y complejo concepto de la experiencia corporal?

Si partimos de la comprensión de que la experiencia corporal surge en el entramado de estos tres cuer-

6 Cabe recordar aquí que un objeto como el reloj puede modificar los fundamentos de una cultura indígena, donde sus regulaciones de tiempo no son de carácter sucesivo, sino de carácter cíclico. $\mathrm{O}$ un espejo, en aquellas comunidades que tienen como referencia fundamental al otro, introyecta una nueva noción del cuerpo.

7 “En tensión con...". El signo - 000 aquí hace referencia al conflicto inherente a una relación dialéctica-dialógica. Conflicto que se expresa en relación de fuerzas a la vez "antagonistas"-"complementarias". pos -no de ellos exactamente, sino de sus relaciones-, a partir de ellas podríamos configurar la experiencia corporal desde tres posibles dimensiones o planos cuyas relaciones se co-determinan y re-elaboran en sinergia: la extensión, la introyección y la proyección. Al revisar cada una de ellas, identificamos unos elementos estructurales de la experiencia corporal, cuyo abordaje, desde la clase de educación física, exige un fuerte replanteamiento.

\section{Extensión (dimensión extra-corporal)}

Pero el fenomenólogo necesita, a nuestro juicio, llegar a la simplicidad máxima. Creemos, por consiguiente, que resulta interesante proponer una fenomenología de la concha habitada.

Gastón Bachelard (1975, p.107)

$\mathrm{Al}$ analizar los principios de la percepción planteados por la escuela de la Gestalt, llegamos a la comprensión de que el mundo del hombre no es un mundo de objetos; es un mundo de relaciones entre objetos y sujetos. Estas relaciones abstractas, simbólicas, que emergen de ese conjunto de relaciones, entretejen una red de interdependencias entre el cuerpo en el espacio, el cuerpo y los objetos, y el cuerpo en el tiempo, que se configuran como estructuras fundamentales de la experiencia del mundo de la vida. (Schutz, 2009, p.113)

El cuerpo en el espacio: ¿cuál es el espacio del que hablamos los educadores físicos? ¿El espacio rectangular de la cancha? ¿Quizá el espacio delimitado por los separadores del carril de competencia? Derecha, izquierda; arriba-abajo, delante-atrás, son datos epicríticosobjetivos $^{8}$ que nuestra percepción, así educada, privilegia. Pero el espacio no se restringe a los planos, ejes, direcciones, trayectorias y distancias en que se mueve un cuerpo. Así pues, como lo plantea Merleau-Ponty:

La percepción del espacio y la percepción de la cosa, la espacialidad de la cosa y su ser de cosa, no constituyen dos problemas distintos [...] La espacialidad del cuerpo es el despliegue de su ser cuerpo, la manera en que se realiza como cuerpo. (1985, p. 165)

8 Alexander Luria, retomando a Head, distingue dos niveles en la percepción. Uno, protopático, considerado primigenio, muy ligado a la emoción, que da cuenta del carácter subjetivo en una percepción, y el nivel epicrítico, que da cuenta e informa de los datos objetivos dados en una percepción, tales como colores, trayectorias, distancias, etc. (Luria, 1984) 
El espacio es horizonte en expansión, es la extensión o contracción de mis límites; entrelaza y configura el escenario de nuestras relaciones con los sujetos y los objetos. Es la espiral de mi adentro y mi afuera. Es vértigo. Estas y otras características protopáticas (subjetivas, muy ligadas a la emoción) del espacio son nutriente y fundamento de la experiencia corporal.

El espacio tiene, cuando menos, un doble carácter. Es, a la vez, un espacio físico-material y un espacio cultural. Como espacio físico, se nos presenta en una configuración que delimita las relaciones entre los objetos, condicionando, desde su disposición, las posibilidades de interacción de quienes habitan ese espacio. Pero desde su carácter cultural, un espacio y los objetos que lo conforman están delimitados por las reglas de uso, haciendo que el sentido y significado que se le atribuye a ese espacio esté condicionado por las formas de orden y jerarquía que de él dispone la cultura, dando unidad, sentido y coherencia a las acciones de quienes lo habitan. Este doble carácter se concreta en un ámbito a la vez biofísico, social-regulativo y subjetivo-experiencial.

Los estudiosos del desarrollo humano han coincidido en afirmar la existencia de una primera zona, ámbito o espacio donde nos desenvolvemos, donde estructuramos nuestro espacio en el espacio del mundo, y que configura nuestra experiencia corpórea. Es así como nos dice Schütz:

En toda situación me es dado únicamente cierto sector del mundo. Solo parte del mundo está al alcance efectivo de mis acciones; pero alrededor de este ámbito se diferencian otros ámbitos de alcance recuperable o asequible, cuyas esferas de alcance muestran una estructura tanto temporal, como social. (Schütz, 2009, p. 112)

Pero, ¿cuál es ese primer espacio, que es el nuestro, y que propicia nuestro desarrollo? Lo comprendemos cuando observamos a aquel que en una piscina juega, explora en el agua y se divierte aprendiendo gradualmente sus ritmos respiratorios, su temperatura, sus ajustes segmentarios, los cambios en sus relaciones espaciales (adelante donde era su arriba, etc.) y el tiempo: la cámara lenta en las acciones, la ingravidez, así como estar viviendo, en un nivel alegórico, su retorno al vientre materno. La imagen anterior se contrasta con lo conductistas que son los métodos comúnmente empleados en la enseñanza de la natación; un nadador formado en los estilos técnicos se pondrá neurótico y no podrá nadar si no encuentra para sí un carril donde pueda hacerlo en línea recta9 9 .

Ese "rincón del mundo, pequeño universo", entendido a la manera de Bachelard, ese espacio de seguridad, de protección, nuestro albergue, que nos permite regenerar, reinventar el vientre materno, es nuestra casa, nuestro hogar.

La casa alberga el ensueño, la casa protege al soñador, la casa nos permite soñar en paz (...) los lugares donde se ha vivido el ensueño, restituyen por ellos mismos en un nuevo ensueño. (...) Sin la casa, el hombre sería un ser disperso. Antes de 'ser arrojado al mundo', el hombre es depositado en la cuna de la casa. (Bachelard, 2000, p. 30)

Es en esta comprensión donde tiene sentido ese espacio originario, como germen de la comunidad, del que son testimonio las malocas indígenas, "pequeños universos".

Esto se ilustra en la perspectiva desde la cual interpretan otras culturas el espacio que habitan: cuando un indígena habla de su territorio, no se refiere a su delimitación geopolítica (como es el Estado-nación), se refiere a los entramados simbólicos que le conectan vivencialmente con los imaginarios que lo habitan desde su historia, su ecología y su sentido de vida (Pinzón, 1997, p. 194).

Así pues, no solo ocupamos un lugar en el espacio: ocupamos un espacio y un tiempo en el espacio y el tiempo de los otros, en el tejido de relaciones sociales, micro y macro. Por ello, necesitamos y buscamos ocupar un espacio y un tiempo en ese tejido, sea a nivel familiar, a nivel laboral, sociopolítico, y cuando ese espacio se nos niega, hay allí una relación de poder que nos violenta. Aunque desborda la delimitación del presente análisis, quede por lo menos consignado que el espacio, como tejido de relaciones, conlleva implícitas unas relaciones de poder que configuran la experiencia corpórea.

9 No apunto a negar el desarrollo del deportista y lo que gana con el entrenamiento, sino a la reflexión sobre el "a costa de qué" se da ese rendimiento. El no poder "volver al vientre materno". Se da en este caso un desplazamiento del "acto por sí" al "acto para", donde la significación del acto por sí es inherente a él. En el "acto para", su significación se impone desde fuera, dándose un mecanismo de expropiación del cuerpo. 
En relación con los objetos, cabe aquí la crítica de Jean Baudrillard a las restricciones funcionales que se asignan a los objetos en nuestra cultura, donde su carácter simbólico está supeditado a su funcionalidad en el espacio (espacios reducidos: sofá-camas, gabinetes ocultos en anaqueles, "las cosas se repliegan y se despliegan, desaparecen y entran en escena en el momento deseado...", así como los objetos en serie, homogenizados, estandarizados, "puesto que no significa más que la liberación de la función del objeto, y no del objeto mismo" (Baudrillard, 1969, pp. 15-17).

Pero al liberar la función del objeto, su proceso de significación por el ser humano que se relaciona con los objetos, se empobrece. Por esto es fundamental que en aras de un enriquecimiento experiencial, se posibilite la divergencia de significaciones. Por ejemplo: ¿un balón anaranjado solo sirve para jugar baloncesto? 0, ¿un desplazamiento con los ojos vendados solo tiene sentido en las relaciones espaciales que suscita? ¿No puede relacionarse con un relato, una metáfora, o privilegiar las formas de relación entre los estudiantes? Cabe recordar que los objetos se hacen significativos, nos dice Donald Winnicott (1986), dentro de un "espacio potencial" en el que representan la transición entre la "dependencia de la madre" y la independencia del sujeto. El aro, ¿es solo eso? La pelota, ¿es una bola tan solo? ¿Qué nos dicen al respecto las teorías sobre el juguete?

Son claras las observaciones en relación con el juego simbólico hechas por Piaget, en las cuales los niños (así como se puede evidenciar en las prácticas de los artistas) trascienden el sentido funcional-utilitario de los espacios y los objetos. Así, para un niño un árbol puede ser un "Challenger"; y una pelota -como para el escultor una roca- guarda en sí todas las formas, todas las posibilidades. Un lienzo en blanco, una alcoba "vacía", no están vacíos. En las relaciones e interacciones humanas conforman redes de significado.

El hecho de que el ser humano se haya resistido permanentemente a aceptar la realidad tal cual es, o como interesa a diferentes grupos de poder, yendo más allá del sentido asignado a los objetos, ha sido uno de los motores de su desarrollo. Así pues, la forma en que se posibilite el manejo divergente del espacio y los objetos, acorde con significados divergentes también, redundaría en el enriquecimiento experiencial del ser humano.

\section{La experiencia del tiempo}

Siguiendo la costumbre de la antigua epistemología, sugeriría aquí la cuestión de si el tiempo es sólo una relación que hace el hombre, y no algo que exista de una manera real e independiente de él. Falso planteamiento cuyo defecto reside entre otras cosas, en partir de un individuo como sujeto del conocimiento. (Elías, 1989, p. 21)

¿De cuál tiempo hablamos los educadores físicos? ¿Del tiempo del cronómetro? ¿Del tiempo de la experiencia? Al parecer en el deportista son el mismo. ¿Cuál es nuestro afán por domesticar el tiempo? ¿De sujetar los ritmos circadianos a los ritmos horarios? ¿Por qué nos aferramos al tiempo programático, que distribuye los saberes divorciándolos del tiempo de la experiencia? Consideramos pertinente la siguiente reflexión de D. Denis:

En lugar de que los niños vivan el espacio y el tiempo, los educadores se los hacen aprender: esto lleva a la construcción de un sistema simplista de referencia, a una estructura cerrada y petrificada. (Denis, 1986, pp. 52-53)

Si bien el cómo se comprende el tiempo es un aprendizaje social (Elías, 1989, p. 21), en diferentes culturas se hace experiencia que se interpreta de manera diferente. Por ejemplo, entrevistando a un indígena sioux, Edward Hall escribe:

¿Qué pensaría usted -nos dice- de un pueblo que no posee una palabra para el «tiempo»? Mi gente no posee palabra para expresar «después» o «esperar». No saben lo que es esperar o llegar tarde (...) (Hall, citado en Elías, 1989, p. 153)

Para quienes hemos vivido en una sociedad donde el tiempo sucede en un reloj, es muy difícil comprender que haya otros que vivan el tiempo de manera distinta, como un acontecer, y más aún, que nosotros mismos podamos experimentar el tiempo de manera tan diversa, según nuestro momento de desarrollo, nuestro estado emocional, o las formas de relación en que nos situamos.

Desde su comprensión como una estructura fundamental de la experiencia, el tiempo no es (necesariamente) ese antes o después de: es cascada que fluye y acontece. Es así como los tiempos del erotismo, la danza y el juego rompen con las delimitaciones del tiempo real, que siendo vivido como un tiempo sucesivo y con- 
tinuo, se alterna con momentos "vacíos" que hay que llenar para conjurar el tedio. Desde el tiempo del juego -tiempo que acontece-, una tarde puede ser toda una vida. "No hay que decir, pues, que el cuerpo está en el espacio, ni tampoco que está en el tiempo. Habita el espacio, habita el tiempo" (Merleau-Ponty, 1985, p. 152).

Es el instante del presente donde "soy", y en el antes y el después, la nada. La nada de la que si algo queda es la experiencia, o la nada de la potencialidad, de la posibilidad (Bachelard, 2002, p. 29). Es en la fuerza del instante donde confluyen las tensiones del acervo frente a las posibilidades de su puesta en acto. En esa confluencia de condiciones se teje la situación en que soy.

Mi experiencia del mundo de la vida también está ordenada temporalmente: la duración interior es un fluir de vivencia que surge de fases presentes, retentivas y protentivas, como también de recuerdos y expectativas. Está intersectada por el tiempo del mundo, el tiempo biológico y el tiempo social, y se halla sedimentada en la sucesión única de una biografía articulada. (Shutz, 2009, pp. 113)

En las prácticas corporales, como posibilidades experienciales, hemos visto cómo, desde la perspectiva de la experiencia corporal, el tiempo y espacio van más allá de los mecanismos de regulación (y control) del ser, a partir de su estar. Podría decirse, parafraseando a Morin, que habito el espacio, habito el tiempo que me habita; por ende, podemos darnos cuenta de que la extensión, dimensión "externa" a mi ser, también me conforma en mi ser interior, se introyecta en mí, configurando mi experiencia corporal.

\section{La introyección (dimensión intracorporal)}

En la tensión permanente entre natura y cultura, en la tensión permanente entre los imperativos biológicos y los imperativos sociales, emerge la introyección como un ámbito experiencial, que da autorreferencias desde la sensorialidad, la percepción, la emoción, los criterios valorativos, el reconocimiento de sí, de sus posibilidades y restricciones, teniendo como fundamento los significados que se generan en las diferentes experiencias corporales, así como las posibilidades de construcción de sí.

Si bien el planteamiento positivista, desde la relación órgano-función, hace una reducción de la sensibilidad al asignar a cada órgano sensorial la función de captar unos niveles de onda específicos, que se toman como medios para acceder al objeto que está afuera, en la realidad objetiva (Merleau-Ponty, 1985, pp. 93), esta visión clásica se replantea desde varias perspectivas. Como nos lo recuerda una poetisa:

El cerebro es ciego, sordo, mudo, insensible (...) todo lo que recibe son impulsos eléctricos del cuerpo, que es un transductor. (...) Cuando los científicos y filósofos hablan del mundo real, están hablando de un mito, una ficción conveniente. El mundo es una construcción del cerebro, basada en la información sensorial recibida, que es solo una pequeña parte de la que está disponible. (Ackerman, 1992, pp. 370-371)

Desde este planteamiento se comprende que el carácter de la sensibilidad no es pasivo ante "el objeto", sino que opera en la traducción, selección y análisis de lo percibido. Los sentidos se caracterizan por ser: sinestésicos, cinestésicos, autoestimulantes y constructivos.

Es así como, en relación con el carácter sinestésico, en el proceso perceptivo se dan imágenes íntegras, que rebasan los marcos de las sensaciones aisladas, mediante el trabajo mancomunado de los órganos de los sentidos y la síntesis de sensaciones sueltas en el funcionamiento en complejos sistemas de conjunto (Luria, 1984, pp. 58). Este carácter de la "sinestesia" (del griego $\sin =$ integrar, junto, y astesis = sensación) podemos evidenciarlo en las observaciones siguientes:

La mano, que es centro táctil, crea, piensa casi por sí sola. La vista resbala sobre el universo, palpa los objetos. La vista nos hace dudar, el tacto nos da la certeza. El oído, el más abierto y sensible de los sentidos, saborea con especial atención al lenguaje y la música. La lengua no solo discrimina lo dulce, lo salado, lo ácido y lo amargo, sino que los integra y en conjunto con el olfato, dan infinidad de posibilidades de gustar, de sentir placer. La voz que se acompaña del acto se hace a nuestros ojos cierta. La voz, el grito, la más grande emanación del cuerpo, nos expande, nos estira, extiende, agiganta... y nos delata. ¿Por qué separar entonces al gesto de la palabra?

El carácter sinérgico de los órganos de los sentidos posibilita una versión enriquecida de la realidad, con mayores posibilidades de significación. Los sinestesistas, esos privilegiados que integran las diferentes sensaciones de manera indiferenciada, combinan escultura, pintura, poesía, música, en un juego de mezclas sensoriales sin fin. Sería pertinente retomar en las clases de educación física aquellas prácticas y procesos que po- 
sibilitan procesos sensoriales de carácter sinestésico, que posibilitan el darse cuenta de sí mismo, ampliando el rango de nuestra conciencia.

El carácter de la cinestesia (de kiné = movimiento, $\mathrm{y}$ astesis = sensación) (Luria, 1984, p. 24), nos recuerda la riqueza sensorial del cuerpo, siempre latente, siempre dispuesta a ser estimulada. Nos dice Diane Ackerman:

Por conveniencia, y quizá con un encogimiento de hombros mental ante las demandas excesivas de la vida, decimos que hay cinco sentidos. Pero sabemos que hay más, y querríamos explorarlos y canonizarlos. (1992, pp. 368-370).

En una cultura dada a la objetivación del mundo, los referentes externos son imperativos, por lo cual se privilegian los sentidos externos, sobre todo los de distancia (vista y oído). Así pues, los sentidos propioceptivos (sentido articular, muscular, del equilibrio, de orientación) y los sentidos interoceptivos (hambre, sed, fatiga, sueño) se ignoran, por desconocimiento o por descuido, y no son trabajados, no son estimulados ni desarrollados. ¿Nos hemos planteado las incidencias de la no exploración de los sentidos propios? ¿Cómo puede dar cuenta de su sentir el niño, el hombre que no es consciente de sus tensiones musculares y viscerales, tan ligadas a la emoción? ¿Cuáles referentes tiene el niño, el joven desde sí mismo, cuando no puede darse cuenta de su propio sentir? El fuerte carácter experiencial de las sensaciones propias ha sido descuidado por la educación física en nuestra cultura, que privilegia la adaptación al entorno (los ajustes corporales a las condiciones espaciales-temporales del entorno). Se hace necesario revertir esa tendencia involucrando en las clases, aquellas prácticas corporales que privilegien la propiocepción.

Otro elemento clave a tener en cuenta, es que los sentidos se autoestimulan. Cada uno de nuestros sentidos construye su máximo deleite: el oído: música. El tacto: eros. El gusto: cocina selecta. El olfato: perfume. La mirada: pintura, formas. Y de los sentidos propios e internos, ¿cuántos deleites estamos perdiendo por no conocerlos? ¿Cuáles posibilidades de enriquecimiento de nuestra experiencia corporal, así como de comprensión y resignificación del mundo, están latentes, a la espera de ser vividas? Deportes "extremos", que tienen en común las fuertes descargas de adrenalina, el riesgo, y a la base, el vértigo como fundamento sensorial por explorar. $\mathrm{O}$ la reconfiguración y combinación de viejas prácticas deportivas, tales como el tae-bo, el parkour, las artes marciales mixtas, son prácticas corporales emergentes que exploran nuevas sensibilidades, nuevos lenguajes, nuevos ambientes, nuevas formas de interacción.

Los sentidos son constructivos: no han sido "objetos" en la evolución biológica ni en la evolución cultural. Han determinado de manera activa la evolución biológica, modelando al hombre más allá de sus especificidades sensoriales, jalonando las culturas y su historia. Se han ido modelando a sí mismos, en tanto han modelado el mundo del hombre ${ }^{10}$.

¿Por qué educar entonces los sentidos separándolos de la acción, de la palabra, la expresión y sus significados? Hemos visto que desde sus características cinestésicas, sinestésicas, autoestimulantes y co-constructivas, los sentidos no son receptores pasivos del entorno, sino generadores de significados que se expresan en diferentes posibilidades comunicativas siempre en relación con otros: música, poesía, erotismo, lucha, degustación, juego, etc. Por lo tanto, desde estos fundamentos, el término de "órganos de los sentidos", en tanto que a la vez capta, pero también busca comunicar, se queda pobre. Así, desde la perspectiva de la experiencia corporal, ¿no sería mejor hablar de "sistema senso-expresivo"?

Esa doble condición receptiva-expresiva, propia de nuestros sentidos, nos caracteriza como seres sociales, que nos desarrollamos en las posibilidades de interacción con otros, lo cual nos remite a otra dimensión de la experiencia, que provisionalmente denominaremos proyección.

\section{Proyección (dimensión intercorporal)}

"La armonía oculta, como la lira y el arco, admite sucesivamente la tirantez y la flojedad".

Heráclito. Fragmentos

El acto comunicativo del cuerpo con su entorno social se da en un campo de tensión ( 6000 ) ${ }^{11}$ entre el código lingüístico preexistente, exterior a él, y la ex-

10 En su Historia natural de los sentidos, D. Ackerman ilustra profusamente el carácter de co-construcción de los sentidos y la cultura.

11 "En tensión con". El signo cia al conflicto inherente a una relación dialéctica-dialógica. Conflicto que se expresa en relación de fuerzas a la vez "antagonistas"-"complementarias". 
presión que surge de la interioridad de las pulsiones, deseos, sueños, emociones y saberes que sustentan la dimensión corporal del lenguaje, por cuanto es experiencia que "nace de la lucha y de la colaboración entre la reflexión consciente y las necesidades inconscientes" (Gay, 1992, p. 189). En primera instancia retomaremos, pues, el emocionar como fundamento de la experiencia:

Emocionar: las emociones emergen en el desarrollo del ser humano como un primer sistema de interacción, que le permite regular de manera flexible sus estados internos en sus interacciones con el entorno y sus relaciones sociales. (Adolphs, 2002, p.137). Desde una perspectiva fisiológica, las emociones surgen en la dinámica emergente de la interacción entre el sistema nervioso y el sistema endocrino, en la integración de imágenes y sensaciones, que ocasiona un determinado estado orgánico y psíquico, el cual es interpretado subjetivamente.

Pero hay procesos sociales que condicionan el desarrollo emocional, tales como la privación en la estimulación táctil, el entorno agresivo o tranquilo en que nos desenvolvemos (Montagu, 1978, pp. 97-109), configurando un acervo de experiencias que nos permite interpretar nuestro entorno y actuar en él.

Las emociones se van configurando como estructura fundamental de la experiencia, en un campo de tensiones entre el estado interno y el entorno, en la necesidad, por un lado, de tomar posición, actitudinalmente hablando, frente a las exigencias-presiones del entorno, y por otro, de comunicar (dar cuenta de) un clima interno, como principio de una interacción con los demás. Así pues, en esta tensión dialógica de la palabra del cuerpo con la palabra que se "infiltra" en el cuerpo, el lenguaje da forma y sentido a las experiencias corporales. El cuerpo que está en la palabra sería así el fundamento de la comunicación cinética que, desde un basamento somático, acompaña, refuerza y trasciende la comunicación verbal.

Esta comunicación cinética, como la lingüística, se daría en tres niveles: un nivel indicial, un nivel simbólico y un nivel sígnico (Picard, 1986).

Al nivel de indicio, como forma primitiva de comunicación, una señal cinética no implica una acción codificadora generalizable y está fuertemente ligada y dependiente de la circunstancia en que nace, para su comprensión. Así mismo, no implica el deseo consciente de comunicar.

Experiencias de K. Shimoda revelan un nexo profundo entre un estado emotivo y la mímica corporal. Por lo tanto, si el cuerpo revela tal o cual emoción, es posible establecer una relación entre determinados afectos (p.e. alegría, tristeza) y determinados significantes cinéticos: la postura, la géstica del rostro, permiten leerse (siempre en un contexto particular) como indicios expresivos de una emoción. Al parecer, hay una percepción no consciente de esos indicios capaz de provocar una reacción en quien los lee, aún cuando este no pueda hacer una clara explicación de lo leído (Picard, 1986, p. 38 y ss.).

Al nivel de símbolo, la señal kinética alcanza un segundo nivel en el que la función semiótica, por la cual el significante (el "objeto") ya genera un significado, aún no del todo codificado, aún dependiente de una analogía, una imitación (p.e. cuando alguien se tapa la nariz ante un olor nauseabundo). "No se puede hablar de símbolo sino en la medida en que un significante corresponde a un mismo significado para los individuos pertenecientes a una misma cultura o subcultura" (Picard, 1986, p. 126).

Al nivel de signo, un signo de carácter kinético puede ser de origen indicial o simbólico, pero "es su empleo con el fin de comunicar, lo que le hace signo". Puede ser la acentuación voluntaria, con el fin de comunicar, de un comportamiento originalmente indiciario: la ' $\mathrm{V}$ ' de victoria, la señal de auto-stop, el tomar la mano de la novia en la calle (lo cual indica posesión), son signos aprendidos y generalizados, trasladables a contextos más generales de una cultura. Aún así, habrá diferencias culturales en la manera de efectuar un signo (p.e. "ven" y "vete" se expresan de manera opuesta en culturas de África y Tailandia) (Picard, 1986, p. 126). Así pues, en los tres niveles, la kinética permite no solo dar cuenta de lo percibido externamente, sino dar(se) cuenta, identificar, codificar, interpretar la realidad interna (el plano intrapersonal o introyectivo).

En la tensión dialógica ( -2000 ) entre la expresión personal frente al código dado por la cultura (palabra basada en el cuerpo 0002 palabra infiltrada en el cuerpo), los lenguajes corporales $600 \mathrm{C}$ los verbales, entre lo interior 6000 lo exterior, se estructura la proyección del sí mismo hacia los demás, posibili- 
tando el enriquecimiento experiencial. Por ello es necesario que los educadores físicos reconozcamos esa dimensión comunicativa que se entreteje en la clase, en el desarrollo de las prácticas por los estudiantes, en sus interacciones recíprocas, y, orientándola de manera pedagógica, la retomemos como fundamento de la construcción de sentido, posibilitando su enriquecimiento experiencial.

\section{A modo de síntesis}

- Desde lo planteado en estas páginas, podemos comprender la unicidad, la raigambre existente entre las tres dimensiones de la experiencia aquí esbozadas: la extensión, que nos indica el carácter relacional entre el espacio, el tiempo y los objetos, la introyección, que expresa el carácter dinámico de la subjetividad, y la proyección, como dimensión donde se pone en juego la intersubjetividad, como elemento fundante de la experiencia corpórea.

- Del reconocimiento de las interdependencias, codeterminaciones y reelaboraciones en que se configuran estas tres dimensiones (posiblemente arbitrarias) que cruzan los cuerpos biológico, social y subjetivo, podemos hacernos a un modelo (aún incompleto, claro está) que nos aproxime al concepto de la experiencia corporal como experiencia de ser cuerpo, a partir de una sensibilidad de carácter dinámico, constructivo y autorreferencial.

- Podemos plantear como principio que la experiencia corporal surge a partir de diversos campos de tensión, en tanto que el cuerpo se construye en la tensión dialógica entre el adentro y el afuera, entre natura y cultura, entre código y deseo, significándose y significando los espacios y los tiempos que le atraviesan, generando arraigo y referentes desde los cuales sentipensactuar (en palabras de nuestra maestra Judith Jaramillo). Es desde este carácter significativo desde el cual se configura la experiencia, desde los cruces del espacio propio, el del otro y los que la cultura señala.

- Dado que la Educación Física retoma las prácticas corporales y desde una intención pedagógica las toma como mediaciones para propiciar el desarrollo del potencial humano, se hace necesario privilegiar aquellas prácticas y procesos que propicien un enriquecimiento de la expe- riencia corporal, posibilitando el desarrollo de la propiocepción y la intercepción, bajo la comprensión de que la sensorialidad es fundamento central de la experiencia corporal.

- En tanto que la experiencia corporal se nutre de la acción con sentido, es pertinente considerar las tareas de clase no como actividades aisladas, reducidas a su carácter funcional (sin desconocerlo tampoco, por supuesto), sino mirarla como una unidad dinámica entre el estudiante y su entorno, en la cual se teje una situación significativa donde el estudiante pone en juego su acerbo y condiciones frente a las condiciones y exigencias planteadas por la situación.

- Es en la dinámica de la acción (acción de la cultura-acción del sujeto o en nuestro marco: acción del maestro-acción del estudiante) donde se configuran las tareas de la clase como tejidos situacionales. Es allí donde el maestro le da a la tarea unas condiciones que posibiliten la superación del carácter funcional del movimiento, ligando a las acciones una metáfora, un reto al pensar del estudiante, una dificultad a las formas de interacción de los estudiantes, haciendo explícita una contradicción a superar, desde una intención pedagógica orientada al enriquecimiento de la experiencia corporal.

\section{Referencias}

Abagnano, N. (1997). Introducción al existencialismo. Bogotá: Fondo de Cultura Económica.

Ackerman, D. (1992). Historia natural de los sentidos. Buenos Aires: Emecé Editores.

Adolphs, R. (2002). Emoción y conocimiento. Barcelona: Tusquets.

Bachelard, G. (2000). La poética del espacio. México: Fondo de Cultura Económica.

Bachelard, G. (2002). La intuición del instante. México: Fondo de Cultura Económica.

Baudrillard, J. (1969). El sistema de los objetos. México: Siglo XXI Editores.

Chomsky, N. (2002). El control de nuestras vidas. Bogotá: Fica.

Deleuze, G. y Guattari, F. (1974). El antiedipo. Barcelona: Paidós.

Denis, D. (1986). El cuerpo enseñado. Buenos Aires: Paidós.

Gay, P. (1992). La experiencia burguesa de Victoria a Freud. Tomo 1. México: Fondo de Cultura Económica.

Huxley, A. (1998). Nueva visita a un mundo feliz. España: Ed. Sudamericana. 
Luria, A. (1984). Sensación y percepción. España: Ed. Martínez Roca.

Merleau-Ponty, M. (1985). Fenomenología de la percepción. España: Ed. Península.

Not, L. (1994). Pedagogías del conocimiento. Bogotá: Fondo de Cultura Económica.

Picard, D. (1997). Del código al deseo. Buenos Aires: Paidós.

Pinzón, C. (1997). El cuerpo-imagen. Maguaré, Revista de la Facultad de Antropología. Universidad Nacional. No 14. pp. 191-238.

Schütz, A. y Luckman, T. (2009). Las estructuras del mundo de la vida. Buenos Aires: Amorrortu.

Winnicott, D. (1986). Realidad y juego. España: Gedisa.

Páginas web:

www.wikipedia.org

Imágenes diseñadas en Power Point por el autor. 